\title{
Schelling y la metafísca de la voluntad
}

\author{
Schelling and the metaphysics of will
}

\author{
FERNANDO PÉREZ-BORBUJO ÁLVAREZ \\ Universidad Pompeu Fabra, Barcelona (España)
}

RECIBIDO: 19-07-2011

APROBADO DEFINITIVAMENTE: 13-08-2011

\section{RESUMEN}

En el presente artículo haremos un breve recorrido por la historia de la metafísica del siglo XIX, partiendo del giro que se produce en la concepción del ser en el pensamiento de Schelling, más concretamente, en su ensayo sobre la libertad (1809). Schelling aparece como el fundador de la nueva metafísica, una metafísica que entiende el ser como voluntad, concepción que subyace al pensamiento de Schopenhauer y Nietzsche. Redescubrir la filosofía de Schelling como la fuente inspiradora de cierto pensamiento filosófico más allá de la figura imponente de Hegel nos permitirá enriquecer nuestra visión de la historia del pensamiento filosófico del XIX.

PALABRAS CLAVE

IDEALISMO ALEMÁN, HISTORIA DE LA FILOSOFÍA, METAFÍSICA, VOLUNTAD, SIGLO XIX

\begin{abstract}
In the present article we'll go on a very short walk through the history of metaphysics during 19th century, setting off at the «turn» in the concept of being that took place in Schelling's thought, more concretely in his essays on liberty (1809). Schelling appears to us as the founder of a new metaphysics, one in which being is understood as will, concept which underlies Schopenhauer's and Nietzsche's thought. Rediscovering Schelling's philosophy as the source
\end{abstract}

(C) Contrastes. Revista Internacional de Filosofía, vol. XVII (2012), pp. 229-246. ISSN: 1136-4076

Departamento de Filosofía, Universidad de Málaga, Facultad de Filosofía y Letras Campus de Teatinos, E-29071 Málaga (España) 
of inspiration for these thinkers, beyond the impressive figure of Hegel, will allow us to enrich our vision of history of philosophical thought during 19th century.

KEY WORDS

GERMAN IDEALISM, HISTORY OF PHILOSOPHY, METAPHYSICS, WILL, 19TH CENTURY

\section{LA VISIÓN ROMÁNTICA DE LA NATURALEZA: PROLEGÓMENOS DE LA METAFÍSICA DE LA VOLUNTAD}

SCHELling PASARÁ a LA HISTORIA DE LA FILOSOFÍA como el «padre de la metafísica del siglo XIX». Más allá de las disputas canónicas que han rodeado la interpretación tradicional del Idealismo alemán, ${ }^{1}$ según las cuales el movimiento iniciado con la Ilustración, fruto de las guerras de religión que plantean la necesidad de una cultura de la razón formalizada en los argumentos que se puedan verbalizar públicamente -como expone genialmente Kant en su obra ¿Qué es la Ilustración?-, emancipando la razón respecto a la religión y a toda forma de revelación basada en la autoridad externa, culmina en un sistema de razón, una filosofía del absoluto capaz de explicar, partiendo de un principio claro y evidente, el origen del mundo, el decurso de la historia y de la Naturaleza así como la sistematización y formalización del saber humano acuñado en el transcurso de los siglos: una sistematización de las diversas artes, una jerarquización de los saberes, una explicación genética de los mismos, gracias a un principio dinámico: el Espíritu.

El Idealismo alemán, entronizado en el pensamiento de Hegel, sería la culminación de un racionalismo absoluto en el que «todo lo real es racional y todo lo racional es real». ${ }^{2}$ La vida del Espíritu absoluto abarcaría todas las dimensiones de lo existente, desde la Naturaleza hasta el Estado. Este panlogismo, muestra del apetito fáustico de la razón, parece ser el punto final de ese impulso iniciado en la Modernidad con Descartes, quien intenta hacer epoché de toda la cultura heredada por la tradición y la Antigüedad, empezando ex ovo a partir de una verdad cierta y evidente: cogito ergo sum. Como bien dice Schelling en sus Lecciones Muniquesas. Para una historia de la filosofía moderna, «con

1 Kröner, R. (1977), Von Kant bis Hegel, J. C. B. Mohr, Tübingen; Hartmann, N. (1960), La filosofía del Idealismo alemán, Editorial Sudamericana, Buenos Aires.

2 Hegel, G. W. F. Grundlinien der Philosophie der Recht, GW, Rhein-Westfäliche Akademie der Wissenschaften, Felix Meiner Verlag, Hamburg, 1980, Band 14.1, XIX-XX, s. 14 
Descartes se produce un segundo nacimiento de la Humanidad, una vuelta a la infancia» $(S W X, 323){ }^{3}$

Esta filosofía nueva no puede admitir ninguna materia revelada, ningún contenido que no sea producido por ella o semejante a ella. De este modo la dimensión de la fe, como contenido suprarracional de revelación que el creyente admite por medio de una libre adhesión a una autoridad extraña, queda excluida de la razón. No obstante, esa posición originaria de cierta Ilustración pacata se ve superada por el Idealismo alemán, heredero de una forma de ilustración sui generis, la ilustración alemana, mezcla inseparable de filosofía y religión, que en la línea abierta por Lessing afirma que «todas las verdades reveladas tienen que transformarse en verdades racionales si con ello se ayuda al bien de la Humanidad».4

El Idealismo alemán supone el ingente esfuerzo de la razón por digerir el contenido de la Revelación, dando de él una justificación racional. Este esfuerzo de digestión implica una inmanentización del contenido trascendente de la Revelación, a la par que una divinización del hombre, quien con su colosal proteísmo se hace semejante a los dioses. Sin embargo, como ya se refleja claramente en el proyecto cartesiano, dicho titanismo lo es de una voluntad que sólo encuentra consuelo en una certeza canceladora de cualquier forma de duda. En el fondo toda la Modernidad es el proyecto hercúleo de una voluntad que intenta autofundamentarse en sí misma, excluyendo toda forma de alteridad. Esta subjetividad, cerrada en sí misma, intenta apropiarse del mundo por la vía de una racionalización sin límites.

Uno de los efectos más evidentes de las guerras de religión que tuvieron lugar en Europa durante el siglo XVI y XVII fue acabar con la unidad entre Iglesia y Estado, entre población civil, comunidad religiosa y poder estatal. Especialmente virulenta en el contexto de Alemania, los Países Bajos y el norte de Francia, se hizo realidad el vaticinio bíblico de que «entregará a la muerte el hermano al hermano, el padre al hijo; se levantarán padres contra hijos y los matarán». ${ }^{5}$ La consecuencia no fue otra que la necesidad de buscar un nuevo fundamento para la ley de la ciudad, una nueva regla para la convivencia social. Es justamente en ese momento cuando empieza a gestarse el pensamiento de

3 Citaremos la obra de Schelling según la edición y nueva ordenación de Manfred Schröter de las Obras Completas, editadas originariamente por el hijo de Schelling. ( $S W=$ Sämtliche Werke, VII = el volumen, $\mathrm{n}^{\circ}$ de legajo).

4 Lessing, H. (1982), Escritos teológicos y filosóficos, Editora Nacional, Madrid, § 76, pág. 590.

5 Mc 13, 12-13 
los grandes filósofos sociales (de Hobbes a Rousseau) y cuando se entroniza la «tolerancia» como la gran virtud social. ${ }^{6}$

La religión deja de ser el gran cimiento para la construcción de la paz social y se vuelve necesario un nuevo fundamento sobre el cual erigir la sociedad. El protestantismo introduce el libre pensamiento en la interpretación de la Biblia lo que implica que el texto sagrado incluye sentidos ocultos a la interpretación canónica, forjada por la tradición, que ya no tiene una validez universal. Se produce la proliferación de sociedades bíblicas que dará lugar, con el paso del tiempo y debido al nacimiento político del protestantismo, a una multiplicación ingente de familias luteranas. Esta diáspora de la hermenéutica del texto sagrado impulsa a buscar una nueva fuente de revelación, universal, válida para todos los hombres; una revelación que se base en un libro sagrado que no permita una multiplicidad de sentidos equívocos:

Nosotros poseemos -afirma Schelling- una Revelación más antigua que aquélla escrita, que ha alcanzado ya su cumplimiento e interpretación. El único verdadero sistema de religión y ciencia aparecería si la comprensión de aquella Revelación no escrita fuese abierta, no en el mezquinamente reunido estado de algunos conceptos filosóficos y críticos, sino al mismo tiempo en el conjunto de la Verdad y la Naturaleza. No es el tiempo de despertar viejas oposiciones, sino de buscar aquello que yace fuera y más allá de toda oposición. (SW VII, 415-416)

Ya la incipiente ciencia experimental empezaba a descubrir las leyes mediante las cuales la Sabiduría divina había preescrito un curso necesario a la Naturaleza. También la cábala judía, como ha analizado G. Scholem, ${ }^{7}$ junto con el alquimismo de Paracelso o Agripa, ha formulado una extraña filosofía de la Naturaleza que ve en ella el Libro secreto dispuesto por la Divinidad en el que se encierra un saber propiamente universal y salvador.

La Naturaleza había sido en el medioevo la scala Dei, que según la concepción neoplatónica constituye una escala de las criaturas que crece en perfección hasta elevarse, gracias a las potencias angélicas, hasta Dios, al mismo tiempo que Dios desciende emanativamente hasta el último ser inanimado de la Creación. ${ }^{8}$ No obstante, la ruptura del paradigma griego del cosmos como un mundo cerrado, debido a la emergencia de la idea de infinito, sobre todo con Giordano Bruno, produjo una revolución en la forma de entender las relaciones Dios-Mundo. Fue este cambio de paradigma y mentalidad el que condujo a

6 Kamen, H. (1987), Nacimiento y desarrollo de la tolerancia en la Europa Moderna, Alianza, Madrid.

7 Scholem, G. (1996), Las grandes tendencias de la mística judía, Siruela, Madrid, págs. 128-140.

8 AAVV. (1966), La Filosofia della natura nel medioevo: atti del Terzo Congresso Internazionale di Filosofia Medieoevale, Vita e Pensiero, Milano. 
David Hume, en su obra Diálogos sobre la religión natural, a la postulación del carácter hipotético de cualquier forma de conocimiento de Dios a partir de la Naturaleza. ${ }^{9}$ Los famosos argumentos basados en la causalidad, la analogía, la ejemplaridad y el teleologismo, que sirvieron a Tomás de Aquino para formular sus cinco vías de demostración de la existencia de Dios, son criticadas pormenorizadamente por Hume.

Fue Hume el que despertara a Kant, como él mismo dice, ${ }^{10}$ de su sueño dogmático. Su Crítica del Juicio, que ejercerá una influencia decisiva y determinante, tanto en los idealistas como en los románticos, se constituye en la piedra de toque para entender el giro metafísico con el que se inaugura el siglo XIX y que tiene lugar en la filosofía de Schelling. En ese texto Kant lleva a cabo su operación más arriesgada. Después de haber demostrado que en el ámbito de la razón pura el hombre piensa universalmente leyes universales y que, por tanto, alcanza un conocimiento de la realidad natural puramente mecánica -como ya se anunciaba en Descartes y Galileo y después en la mecánica clásica formulada por Newton- se da cuenta de que el hombre es una realidad sobrenatural, sometido a otra forma de legalidad trascendental que no se induce de la realidad ni tiene base empírica alguna, el deber absoluto manifestado en la forma de un imperativo categórico, gracias al cual es libre porque tiene en sí una fuente de acción y autonomía que le sustrae a la férrea ley de la causalidad física, enfrentándose con el terrible desideratum de unir ambas dimensiones, natural y ética, necesidad y libertad. En el arte encontrará Kant el nexo de unión de un hombre escindido. En la obra de arte, producida por un hombre de manera semi-inconsciente, libre pero necesariamente, una forma de producción artística que imita la de la Naturaleza, encuentra el espectador, de manera intuitiva, la promesa fáctica de la unión real de libertad y necesidad, de espíritu y materia.

La belleza producida por el genio es la encarnación de una ley no producida conceptualmente, mediante el entendimiento, sino inconscientemente. ${ }^{11}$ Esa belleza, puesto que no transmite ningún concepto, ningún conocimiento científico, place sin interés, dejando a la voluntad en un estado de suspensión que favorece la contemplación. La belleza se transforma así en símbolo moral, ya que para Kant la peste de toda moral es el egoísmo, el interés partidista de la voluntad. Por eso la máxima aspiración del imperativo categórico es universalizar el egoísmo, el interés, para que sea válido para todos los hombres. Vemos, por tanto, que la belleza se configura desde este momento en el elemento mediador entre la Naturaleza y la ética.

9 Hume, D. (1994), op. cit., págs. 77-85.

10 Kant, I. (1995), op. cit.,§ 46 y 47, págs. 262-270.

11 Kant, I. Crítica del Juicio, § 76, págs. 379-384. 
Esa belleza imita la producción natural de un modo libre. Lo bello natural se plasma en el organismo, en un ser vivo que se comporta como una verdadera obra de arte al ser causa y efecto de sí mismo. ${ }^{12}$ El organismo no se rige por leyes mecánicas sino que se autogenera, autoproduce y autoorganiza, mostrando así su capacidad de supeditar las funciones particulares al bienestar del conjunto. El caso más paradigmático lo encontramos en el propio cuerpo humano, pues sabemos que un sujeto operado de un lóbulo cerebral a causa de un tumor no pierde las funciones que éste tenía adscritas, sino que las redistribuye a través del lóbulo sano. Vemos así de qué modo el organismo se autoorganiza en orden a un fin: el correcto funcionamiento del cuerpo humano. El fin es el que rige la vida orgánica. El aspecto más relevante de la argumentación kantiana radica en su afirmación de que cuando encontramos un individuo orgánico en la Naturaleza encontramos un fin de la misma, algo absoluto en sí mismo que no remite a nada más allá. El organismo aparece ante la razón como un «fin de la Naturaleza», como un individuo en el sentido pleno de esta palabra, algo que, parafraseando la segunda de las formulaciones del imperativo categórico kantiano, no «puede ser tratado nunca sólo como un medio sino siempre como un fin». ${ }^{13}$

Esta presencia del organismo permite a la razón percibir una teleología de la Naturaleza, haciéndole pensar que se encuentra ante un símbolo de la Naturaleza: algo producido por un agente inteligente. La causalidad inteligente se distingue, según Kant, porque en ella «el efecto precede a la causa y es causa de ésta». ${ }^{14} \mathrm{Si}$ un hombre se propone construir una casa pensando en el dinero que obtendrá mediante el alquiler de la misma, resulta evidente que el dinero, representado intencionalmente por la inteligencia, -el último efecto en la cadena de la causalidad física-, es la causa que produce la acción física de ponerse a construir. Lo cual implica que el agente inteligente es capaz de representarse modelos y efectos independientemente de la sucesión temporal que rige la causalidad física. Esta forma en la que el agente inteligente produce o crea -una mera revisión del ideal platónico de la poiesis- permite pensar a la razón

12 Kant, I. Ibíd., § 65, págs. 343-348.

13 Kant, I. (1995), Crítica de la razón práctica, trad. de Miñana y Villagrasa y de García Morente, Sígueme, Salamanca, págs. 49 y ss. Curiosamente, en un ámbito distinto al de Descartes, nos encontramos con una de las definiciones modernas más poderosas de la 'persona', esta vez no en términos de individuo racional o de cogito, sino como fin de la Naturaleza, que se distingue por su organicidad y singularidad. Más tarde, en esta misma línea, Kierkegaard radicalizará la dimensión singular del individuo frente a la categoría hegeliana de 'individuo' como categoría abstracta, reforzando el aspecto de la incomunicabilidad y la soledad, y situando dicha individualización en el ámbito de la esfera religiosa, de la soledad acompañada del ser que se determina por una suspensión de lo ético.

14 Kant, I. Crítica del juicio, § 65, págs. 346-347. 
humana, cuando se encuentra con un organismo en el que todo está supeditado a un fin, que ha sido producido por un agente inteligente.

El segundo punto de la argumentación kantiana que nos importa retener se refiere a la existencia de un fin final (scopus) en la Naturaleza que nos permita hablar de una ordenación de los individuos orgánicos hacia un fin último del desarrollo natural. Ya sabemos que Kant sigue al pie de la letra la afirmación humeana de que no podemos saber nada de la teleología de un modo científico sino meramente reflexivo, ${ }^{15}$ lo cual no menoscaba el hecho de que debemos pensar la Naturaleza como si hubiese sido dispuesta por un agente inteligente, al menos en sus productos orgánicos. ${ }^{16}$

Este punto de la argumentación sobre la necesidad de pensar un fin último de la Naturaleza está referido a la necesidad de articular deber y felicidad. Kant se plantea la cuestión ineludible de si la Naturaleza tiene como finalidad favorecer el desarrollo moral del hombre o si, por el contrario, se mantiene indiferente ante dicho desarrollo. ${ }^{17} \mathrm{El}$ resultado no es otro que la afirmación kantiana de que el fin de la Naturaleza es proporcionar «el mayor grado de felicidad posible compatible con el desarrollo moral del hombre» ${ }^{18} \mathrm{o}$ sea, que la finalidad intencional de la Naturaleza, según Kant, es favorecer el desarrollo libre y moral del hombre, aportando el máximo grado de felicidad posible de acuerdo con esta condición moral. La Naturaleza se guiaría teleológicamente hacia el desarrollo moral del hombre, hacia el ejercicio de la libertad humana sometida al ineludible dictado del imperativo categórico como camino hacia la felicidad. El fin no es para Kant la felicidad humana a cualquier precio (como quizá podría intuirse de una errada lectura de la ética aristotélica ${ }^{19}$ ) sino aquella felicidad empírica que no menoscabe nuestra dignidad moral, nuestra condición

15 Hume, D. (1994), Diálogos sobre la religión natural, Tecnos, Madrid, págs. 187188.

16 Vid. supra, pág.7.

17 Kant, I. (1995), op. cit., págs. 432-438.

18 Ibídem, págs. 439-446.

19 Las historias de la ética gustan de enfatizar el carácter eudaimonológico de la ética según Aristóteles frente al deontológico según lo considera Kant. Desde este punto de vista Kant y Aristóteles se encontrarían en las antípodas el uno del otro. No obstante me parece que esto es tan sólo una visión errada y superficial de nuestra intuición primera a la hora de considerar las categorías de 'felicidad' y 'deber', como si la primera, la felicidad, no fuese para nosotros un deber tan absoluto e imperativo como el deber kantiano, y como si por su parte la felicidad dependiera para Aristóteles de un ideal imaginativo que se deja al libre albedrío del agente moral y no tuviera el componente de someterse al dictado de la virtud, que tiene en la justicia su fundamento. Releer las posturas de ambos autores constituiría un ejercicio necesario para sacar a la ética de su actual 'embarrancamiento'. Cf. Trías, E. (2000), «El único deber», en Ética y condición humana, Península, Barcelona, págs. 109-113. 
de fines de la Naturaleza, dotados de una dignidad absoluta, que no pueden ser tratados como meros medios, sino siempre como fines.

\author{
II. EL «GIRO METAFÍSICO» EN SCHELLING: \\ DEL «SER COMO PRESENCIA» AL «SER COMO VOLUNTAD»
}

En este punto irrumpe la argumentación schellinguiana que no hace sino proseguir la gran intuición kantiana que aparece al final de la Crítica del juicio. Los primeros esfuerzos de Schelling se dirigen a dilucidar el descubrimiento kantiano realizado en sus Principios metafísicos de la ciencia natural (1797), donde, siguiendo a Newton, afirma que todo el proceso natural se fundamenta en la dialéctica entre una fuerza de repulsión y otra de atracción. ${ }^{20}$ La Naturaleza se asemejaría a un movimiento de contracción y expansión, de sístole y diástole, sincronizado y mutuamente enlazado. ${ }^{21}$ Ese movimiento produciría una elevación progresiva desde una naturaleza originaria, pasional y caótica, hacia la luz del entendimiento. Ya Aristóteles, en Sobre el alma, -la primera filosofía natural que nos ha legado la historia- nos habla de reinos que van elevándose paulatinamente desde el mundo inanimado al vegetal, y de éste al reino animal para alcanzar, finalmente, el ámbito humano. ${ }^{22}$ Ambos reinos están unidos dinámicamente ya que, en realidad, no son mas que el despliegue progresivo de lo que los neoplatónicos denominaban el «alma del mundo» (anima mundi). Esta concepción neoplatónica vendría a sostener que en el alma humana persiste y se conserva el alma vegetal, así como el instinto y el alma animales. De igual modo, en su Filosofía de la Naturaleza, Schelling descubre este evolucionismo de lo viviente hacia el hombre, el dinamismo latente de todo lo viviente desde lo inorgánico hasta lo humano. ${ }^{23}$

20 Kant, I. (1991), Principios metafísicos de la ciencia de la Naturaleza, trad. de José Aleu Benítez, Tecnos, Madrid.

21 En este punto, y sólo en este punto, el mecanicismo de la Scienza Nuova, como la denominó Bacon, coincide plenamente con la descripción que de la naturaleza divina como natura naturans, principio de productividad y vitalidad en la Naturaleza, lleva a cabo la teosofía alemana, tal como la encontramos ya en el famoso texto Aurora de zapatero Jacob Böhme, donde la define como el corazón batiente de la divinidad que se despliega por un movimiento alternativo, y enconativo, de sístole y diástole. No hacía mucho se había hecho el descubrimiento de la circulación de la sangre a través del organismo físico que parecía validar toda una tradición mística que habla de lo viviente como hermanado en un caudal sanguíneo, gracias a Miguel Servet, cuya condena suscitó todo tipo de posiciones.

22 Aristóteles, Sobre el alma, 413b-416b.

23 Consúltese la introducción de Arturo Leyte a su traducción de los textos schellinguianos correspondientes a este período de la Filosofía de la Naturaleza que comprende desde 1797 a 1806. Cf Schelling, F. W. J. (1996), Escritos de Filosofía de la Naturaleza, Alianza Editorial, Madrid, págs. 11-61. 
Esta visión de una Naturaleza evolutiva casa perfectamente con el siglo XIX, siglo de la acción y de las grandes mutaciones sociales, de un cambio desde el paradigma mecanicista de la Naturaleza hacia uno biologicista y evolucionista. La visión cósica e inerte de la Naturaleza, como escala casi estratificada de reinos sólidamente asentada, casi arquitectónica, da paso a una visión dinámica de un mundo en continuo cambio y movimiento, sumido en un devenir perpetuo.

Schelling formula la idea de una Naturaleza inseminada por la lucha entre libertad y necesidad, inteligencia y voluntad, oscuridad y luz, que sólo finaliza en el hombre porque sólo en el hombre la voluntad que recorre toda la Naturaleza se ve libre de sí, de su tendencia inconsciente, de su anhelo oculto que emerge ahora, por fin, a la luz. El hombre es libre e inteligente simultáneamente porque ser inteligente es verse libre del instinto; dado que sólo en el hombre lo instintivo se contempla a sí mismo en libertad. En este sentido Schelling define al hombre originario como «mismidad espiritual», voluntad que se contempla a sí misma en libertad ( $S W$ VII, 364-366). Pero no se entienda esta libertad como algo meramente interior, trascendental en el sentido kantiano, sino como libertad encarnada, fruto de la tendencia de una voluntad que la alumbra y problematiza. El hombre es un ser sobrenatural en el sentido ya aludido por la palabra alemana 'sobrenatural' (Über-natur): lo que está en la Naturaleza, sobrevolándola. ${ }^{24} \mathrm{La}$ libertad es la tendencia pasional y erótica hacia la luz y la espiritualización que en el hombre se vuelve libre e inteligente, pero encarnada.

Vemos, por tanto, que Schelling sostiene la idea de la teleología natural esbozada por Kant pero la justifica metafísicamente afirmando que el fin de la Naturaleza es la liberación, la libertad. La voluntad que se debate en todo lo viviente anhela su liberación que sólo alcanza, de un modo problemático y precario, con la aparición del hombre. La Naturaleza es el camino inconsciente de la conciencia, su pasado trascendental. Si pudiese afirmarse que esa voluntad fue originada por la libertad, podríamos decir que la Naturaleza es un «organismo de la libertad», ya que la libertad es causa y efecto de sí misma. Además podríamos llegar a afirmar reflexivamente, más allá de la afirmación kantiana,

24 Un cierto platonismo vulgar, entronizado por una visión errada del cristianismo paganizante, ha creído ver una oposición radical entre materia y espíritu, y ha querido entender lo sobrenatural como algo que está 'más allá' de lo natural, sobrevolándolo sin tocarse con él. Como el espíritu se movía sobre las aguas primigenias, del mismo modo lo sobrenatural sobrevuela lo natural como si temiese mancharse con su contacto, quedar preso de su inercia. En realidad, Schelling piensa que lo verdaderamente sobrenatural es algo que nace de una tendencia interna de lo natural, superándolo. Es en lo sobrenatural donde lo natural deviene consciente y libre de su propia tendencia natural, pero esta libertad tiene en lo natural su base y su cuerpo, su raíz pasional y viviente. Superar el dualismo sigue siendo aquí de vital importancia para la recta comprensión del pensamiento schellinguiano. 
que el Autor del mundo no sólo debería ser inteligente sino, lo que resulta más decisivo, libre, porque sólo siendo libre puede ser un agente moral.

Abandonemos ahora esa línea que he proseguido en mi libro Schelling. El sistema de la libertad ${ }^{25}$ y centremos en el giro metafísico introducido por Schelling con esta concepción de la Naturaleza como ser polarizado eróticamente hacia un fin: ser en devenir. El ser había sido entendido en la metafísica tradicional como inmutable, eterno, inmortal e imperecedero. Ese ser, definido por vía eminentemente negativa, se constituyó en el pilar y el fundamento de toda la metafísica tradicional, ${ }^{26}$ siendo rápidamente identificado con el Dios revelado: el Ipsum Esse. Dios dejó de ser el dios personal, providente, omnipotente y libre; el Dios de Isaac y de Jacob, el Dios de Abraham, y se transformó, en su formulación teológica, en un mero concepto metafísico. Todo lo existente vivía, siguiendo el modelo platónico, porque participaba del ser eterno. Lo temporal participaba de la eternidad mediante una unión precaria, marcada por el nacimiento y la muerte. Nacer era participar del ser; morir dejar de participar de ese ser que ni nace ni muere ni se transforma.

Evidentemente la existencia era histórica, pero el ser era ahistórico. Con el pensamiento de Schelling empieza a pensarse el ser de otro modo. El ser no está acabado de una vez y para siempre; no es algo eterno que permanece impasible ante la historia del mundo, sin verse modificado ni alterado por ella. La Naturaleza muestra en su teleologismo de qué modo el ser natural tiende, internamente, hacia su realización en el marco de la historia natural, y de la historia humana. Este ser no nace como un ser que muestra toda su potencialidad en forma de una presencia eterna, sino históricamente, de manera paulatina. Este ser, lejos de ser mera presencia sustantiva, como quería determinada lectura platónica de Parménides, es movimiento y devenir orientado teleológicamente, o sea, voluntad:

No hay en última y suprema instancia más ser que el querer. Querer es el ser originario (Wollen ist Urseyn), y sólo a éste convienen todos los predicados del mismo: sin fundamento, eternidad, independencia del tiempo, autoafirmación. Toda la filosofía no tiende nada más que a encontrar esta divina expresión. ( $S W$ VII, 350)

El ser es querer, voluntad, y según se revela y manifiesta -puesto que el ser sólo se conoce a posteriori, por sus efectos-, el ser es querer orientado a un fin, aspiración a la libertad, no como fin sino como medio para el desarrollo de una vida moral que alcance el máximo de felicidad posible. El ser anhela su

25 Pérez-Borbujo Álvarez, F. (2004), Schelling. El sistema de la libertad, Herder, Barcelona.

26 Gilson, E. (1967), El ser y los filósofos, EUNSA, Pamplona, págs. 52-76. 
manifestación y, por ello, aspira al conocimiento y a la libertad. Resulta del todo injusta la tesis de Lukács, formulada en su libro El asalto a la razón, de que Schelling es el padre del irracionalismo ${ }^{27}$ porque, como éste afirma repetidas veces, «es el entendimiento el que es la voluntad en la voluntad» (SW VII, 359). Schelling no abroga por un querer ciego, por un deseo pasional autodestructivo, sino por un deseo que se eleva aspirativamente a su fin mediante la libertad y la inteligencia, o sea, un ser que es voluntad.

Este ser es una voluntad universal, cósmica, inconsciente o, mejor dicho, pre-consciente en el ámbito natural; pero consciente y libre en el ámbito humano. La Naturaleza se configura como la historia trascendental de la conciencia humana, como el camino inconsciente que el Espíritu tiene que recorrer para devenir consciente de sí. El siglo XIX descubrió que 'voluntad' y 'conciencia' no eran términos correlativos, sino que la conciencia era el último eslabón en el camino inconsciente de una voluntad que busca su fin.

Este giro metafísico adelanta la concepción heideggeriana del ser y, por supuesto, la de autores como Hans Jonas, que beben de esta metafísica de la finitud ontológica en la que el ser ha dejado de ser un ser eterno, inmortal e imperecedero, para volverse histórico, precario y en devenir. ${ }^{28}$ En esta ontología de la finitud de nuevo cuño, que entiende el ser como voluntad, la permanencia del mundo y la Naturaleza no está desvinculada del libre obrar humano, ni garantizada por un Dios omnipotente, bueno, sabio y eterno; aún menos, puede hablarse aquí del mundo como una realidad eterna e indestructible. Las implicaciones de ese ser que es voluntad se irán desgranando paulatinamente durante el siglo XIX y me limitaré, por razones de tiempo, a glosarlas someramente en dos de sus máximos representantes: Schopenhauer y Nietzsche.

27 Lukács, G. (1976), El asalto a la razón. La trayectoria del irracionalismo desde Schelling hasta Hitler, Grijalbo, Barcelona, págs. 141 y ss.

28 Tanto Hans Jonas como Hannah Arendt, con dos producciones filosóficas tan diversas, beben sin embargo de esta reformulación del ser como ser finito o ser histórico que se produce con el pensamiento de Martin Heidegger y extraen de ella todas sus dimensiones éticas y políticas. Hans Jonas en referencia a un «principio de responsabilidad» que nos compromete moralmente con el legado de una imagen del hombre y de su realización en el mundo físico, en su aspecto ecológico, con respecto a las generaciones futuras; en el caso de Hannah Arendt en la afirmación de que es preciso una ética amorosa de la responsabilidad porque el curso de la historia, como se muestra en los totalitarismos y su diagnóstico, está en manos del hombre. Jonas, H. (1994), El principio de responsabilidad, Herder, Barcelona, págs. 82-91; Arendt, H. (2002), El origen de los totalitarismos, Taurus, Madrid. 


\section{La METAfísica DE LA VOLUNTAD EN SCHOPENHAUER: LA VOLUNTAD QUE QUIERE LA NADA}

En Schopenhauer, claramente preocupado por la cuestión ética, como se deduce de sus críticas y revisiones de la ética kantiana, ${ }^{29}$ la voluntad asume un «carácter trágico». La voluntad se vuelve una instancia transpersonal y cósmica; no un atributo de la persona, sino una realidad metafísica. Para Schopenhauer, fuertemente influenciado por el darwinismo y el nuevo desarrollo de las ciencias experimentales, la voluntad de la Naturaleza es una voluntad egoísta que se autoafirma a sí misma a costa de los individuos. En su obra El mundo como voluntad y representación (1811) pone de manifiesto cómo la inteligencia, el mundo de la representación, es un velo de Maya que engaña al hombre para que se afirme a sí mismo, favoreciendo con ello su autodestrucción a manos de la voluntad universal de vida que pasa por encima de los individuos. ${ }^{30}$ Es en el ámbito de la representación donde tiene lugar la falsa individuación que nos hace creernos seres separados; autónomos, independientes e impenetrables. El descubrimiento que lleva a cabo el sabio es el de que, tras toda la cadena de fenómenos, lo único verdadero es una voluntad universal que busca afirmarse a sí misma. De este modo los individuos, con sus pasiones egoístas, como queda claramente ejemplificado en el ámbito sexual, buscan su propio beneficio sin advertir que en realidad, al igual que ocurría en la astucia de la razón hegeliana, se trata del impulso de la especie que se afirma a sí misma a través del individuo. El individuo acabará muriendo a manos de la especie, por eso Hegel decía que «los hijos son la señal de la muerte de los padres». ${ }^{31}$

Frente a esa voluntad universal que intenta afirmarse mediante el engaño de la individualidad, agitándose agónicamente, nada resta sino dos vías: la del sabio o la del esteta. ${ }^{32}$ En el arte, como bien viera Kant, tiene lugar un aquietamiento pasajero y momentáneo de la voluntad. El hombre hundido en la contemplación se olvida de sí, aquietándose su ansia de acción, aplacándose su sentimiento de carencia y falta. La voluntad se contempla a sí misma en libertad en la obra de arte, con una mezcla de admiración y extrañamiento. Sin embargo, este consuelo

29 Esta pero preocupación ética de todo el pensamiento schopenhaueriano resulta patente en el análisis del libre albedrío y en la crítica del carácter formal del imperativo categórico kantiano llevados a cabo en sus ensayos presentados para los temas propuestos por la Academia Noruega y la Sueca respectivamente, que llevaban por título «Sobre la libertad de la voluntad humana», $\mathrm{y}$ «Sobre los fundamentos de la moral». Schopenhauer, A. (1977), Zürcher Ausgabe Werke, Diogenes Verlag, Zürich, Band VI.

30 Schopenhauer, A. (2000), El mundo como voluntad y representación, trad. de E. Friedrich Saber, Porrúa, México, págs. 133 y ss.

31 Hegel, G. W. F. Die Phenomenologie des Geistes, GW, Band 9, s. 243.

32 Schopenhauer, A. (2000), op. cit., págs. 150-168. 
metafísico del arte es momentáneo porque, enseguida, la voluntad, espoleada por algún infierno interior, se lanza desesperada a la acción. ${ }^{33}$

Sólo el sabio, aquel que mediante el uso de la inteligencia y la razón, depurando la representación, ha llegado a conocer que todo es un velo de Maya; sólo ése es capaz de renunciar a cualquier forma de procreación, al placer sexual, a la astucia de la voluntad, para no proseguir la cadena infernal de esta voluntad sufriente, ingresando en el estado de perfecto desasimiento.

Esta actitud, que Schopenhauer considera se encuentra latente en el budismo y en el cristianismo, lleva a renunciar a la voluntad propia, al egoísmo y a toda forma de deseo, buscando un estado de quietud y pacificación de la voluntad. En realidad la actitud del sabio es la de conducir la voluntad universal, la que rige el mundo, a su consunción, a su aniquilamiento, aplicando la política de tierras quemadas, como hicieran los rusos frente a Napoleón, a las fuentes de todo deseo. La palabra budista 'Nirvana' quiere decir literalmente: gran tierra quemada. El Nirvana es ese estado de beatitud de una voluntad que no desea, resultado de matar el deseo por la vía de un no desear efectivo, que no es fruto ni intención de la voluntad, ya que sino caeríamos en la dialéctica de cierto jesuitismo que quiere alcanzar la anulación de la voluntad mediante el ejercicio de la voluntad; un cierto 'querer no querer' que es una contradicción que fortalece la voluntad misma que quiere negarse. Schopenhauer parece haberse apercibido de la profunda verdad de que la voluntad «prefiere querer la Nada que no querer en absoluto». ${ }^{34} \mathrm{El}$ nihilismo sería la última estrategia de una voluntad que no está dispuesta, en modo alguno, a renunciar a sí misma. ${ }^{35}$

Para el sabio la voluntad egoísta del hombre ciego es la verdadera fuente de dolor en el mundo, por eso está dispuesto a renunciar al estado de verdadera paz, de Nirvana, de bodditshava, movido por una compasión que siente el sufrimiento ajeno como propio e intenta aliviarlo. La compasión del sabio que renuncia a su perfección para aliviar el sufrimiento universal del mundo es, en realidad, una forma solapada de egoísmo metodológico, puesto que el sabio sabe que hay una única voluntad que sufre en el mundo por su autoengaño y que,

33 En realidad no se puede entender el consuelo pasajero que supone el arte para una voluntad de un orden cósmico y metafísico, tal como la formula Schopenhauer, sin haber leído las Investigaciones filosóficas sobre la esencia de la libertad humana y los objetos con ella relacionados (1809) y Las Edades del Mundo (1811-1814) de Schelling.

34 Schopenhauer, A. (2000), op. cit., págs. 313-315.

35 Leído el nihilismo proclamado por Nietzsche desde la evolución durante el siglo XIX de la «metafísica de la voluntad» que ha venido a sustituir la clásica metafísica del ser como presencia, varían sustancialmente su lectura. El nihilismo es la última fase de una voluntad que se opone a «salvarse a sí misma», que «teme renunciar a su propio egoísmo», y con ello hace peligrar su salvación futura. Cf. Löwith, K. (1995), Martin Heidegger. European Nihilism, Columbia University Press, Nueva York, págs. 192-208. 
mientras el velo de Maya no sea descorrido de un modo total, la única voluntad real, que él mismo es, seguirá sufriendo.

\section{NiHILISMO, CREACIÓN Y VOLUNTAD DE PODER EN NiETZSCHE}

Por último, en esta veloz panorámica de la filosofía del XIX, le toca ahora el turno a Nietzsche. Es conocida la filiación de Nietzsche al pensamiento de Schopenhauer, pero no lo es tanto su débito con el pensamiento schellinguiano. Es obvio que Schopenhauer conoció el pensamiento de Schelling durante su estancia en Berlín, al igual que Kierkegaard, y que también Nietzsche conocía, sin duda, muchas de las lecciones de Schelling sobre filosofía de la Naturaleza. Queda patente esta filiación en su obra El nacimiento de la tragedia. Grecia o el pesimismo. Esta obra paradigmática tiene como telón de fondo la religión de la Naturaleza profesada en Grecia y que, como muestra la sabiduría de la tragedia, se basaba en la afirmación de que el valor de lo universal está por encima de lo singular. La vida se afirma a través de individuos que luchan agónicamente por salvarse, pero que sucumbirán finalmente para que la vida se perpetúe. La tragedia celebra este acto por el cual el héroe sucumbe ante el destino en pro de una ley superior de justicia. Esta ley de justicia, esta némesis, es para Nietzsche una ley universal de despliegue vital, una voluntad de vivir.

Extrañamente, esta asunción nietzscheana parece olvidar el esquema schopenhaueriano para acabar afirmando que la voluntad lo que quiere es incrementarse a sí misma, su poder, poniéndolo a prueba en los individuos. ${ }^{36}$ Aquí el individuo no parece renunciar a su voluntad propia con el fin de acabar con la rueda de fuego de una voluntad que nada puede acallar. Por el contrario, Nietzsche asume el carácter prometeico de esta voluntad afirmando que el sacrificio de la propia vida individual debe ser llevado a la exaltación de la lucha heroica para que, de este modo, la voluntad de vida pueda mostrar toda su vitalidad y poder. El héroe griego parece encontrarse aquí en las antípodas de la resignación cristiana o del quietismo del sabio budista que renuncia a cualquier forma de deseo o acción.

En su obra más emblemática, Así habló Zaratustra, poema simbólico de oscura y difícil interpretación, queda patente que el hombre debe sucumbir para alumbrar desde sí al Superhombre (Übermensch). ${ }^{37}$ Sin entrar en las polémicas interpretaciones que rodean la figura del Superhombre me quedaré, no obstante, con la idea de que el Superhombre es algo que debe superar al hombre, atravesándolo (durchgehen), ${ }^{38}$ sosteniéndose sobre él, como en Schelling la voluntad libre sobre la Naturaleza.

36 Nietzsche, F. (1995). El nacimiento de la tragedia, Alianza, Madrid, págs. 56-60.

37 Nietzsche, F.(2003) Así habló Zaratustra, Alianza, Madrid, págs. 389-401.

38 Desde este punto de vista nos es del todo indiferente si tal interpretación tiene que tener 
El hombre debe sucumbir heroicamente, enconando todas sus contradicciones, convocando a la guerra de todas sus potencias interiores, mostrando así la vitalidad superadora del poder propio. ${ }^{39} \mathrm{La}$ voluntad no quiere tan sólo la libertad ni el autoesclarecimiento; la voluntad no quiere la nada o la autoaniliquilación; la voluntad no busca la paz sino que anhela el poder y para ello, como indicó en su día Heráclito, necesita del concurso de la guerra. El poder es el único saber que se muestra en la prueba, experimentalmente, como queda patente en los niños y en las crías de cualquier especie, en su ansia de juego como forma de derroche de vitalidad y manera en la que aprenden a controlar y dominar su poder. ${ }^{40}$

Pero, ¿qué es el poder? Esta pregunta permanecerá sin responder en el presente artículo. Realmente todo querer es un querer el poder, pero ¿qué es el poder? Heidegger, en su obra Nietzsche, relee platónicamente una extraña afirmación que pertenece a los Fragmentos de la voluntad de poder de Nietzsche, en la sostiene que «el arte es el fenómeno más transparente de la voluntad de poder» ${ }^{41}$ Según esta afirmación, qué sea el poder que la voluntad verdaderamente anhela se pone de manifiesto, de un modo intuible, en la obra de arte. Sin entrar a considerar las relaciones de Nietzsche con el arte, la interpretación que propone Heidegger parece violar su propio aserto de que Nietzsche y Platón son dos gigantes opuestos. En realidad, más bien vendría a corroborar, como piensa Eugenio Trías, ${ }^{42}$ que se trata de dos hermanos gemelos, como los Dioscuros, Cástor y Pólux, personalidades complementarias e indesligables la una de la otra. Nietzsche es platónico porque está convencido de que la voluntad de poder es aquella que no se manifiesta en la dominación - síntoma innegable de debilidad e impotencia, como puso de manifiesto Platón en su análisis de la figura del tirano en la Politeía ${ }^{43}$-, sino en la poiesis creadora. Sólo cuando se crea de

una dimensión psicológico-espiritual como hace Lou-Andreas Salomé, o un carácter sociológicopolítico, como el caso de Alfred Baumler. Cf. Salomé, L.-A. (2005), Friedrich Nietzsche en sus obras, editorial Minúscula, Barcelona; $f f$. Baumler, A. (1931), Nietzsche, der Philosoph und Politiker, Leipzig.

39 Véase a este respecto la esclarecedora explicación de G. Deleuze sobre la naturaleza conflictiva de los instintos y el ideal nietzscheano de la conflictividad incrementadora del poder frente al idea de una represión de los instintos en el Occidente cristiano. $C f$. Deleuze, G. (1986), Nietzsche y la filosofía, Anagrama, Barcelona, págs. 84-104.

40 Gadamer tocó parcialmente los misterios de esta voluntad de poder que se manifiesta en el juego en los análisis llevados a cabo en su famosa obra Verdad y Método, pero sin llevar más allá su reflexión, al terreno de una interpretación el marco de una metafísica de la voluntad como la que estamos intentando llevar a cabo en el presente artículo. $C f$. Gadamer, H.-G. (1991) Verdad y Método, Editorial Sígueme, Salamanca, vol. 1, págs. 143-181.

41 Heidegger, M. (2005), Nietzsche, Destino, Barcelona, págs. 72 y ss.

42 Trías, E. (2001), Ciudad sobre ciudad, Destino, Barcelona, págs. 274-276.

43 Platón, República, 565a-569c. 
un modo verdadero y total, sólo en el artista, en el sentido pleno y metafísico de esta palabra, late una voluntad poderosa capaz de suscitar y convocar a la implementación de poder, dándonos conciencia de nuestro poder vital que se manifiesta en la sensación de nuestra propia integridad.

«Poder es creación». Evidentemente el hombre no crea desde la nada, ni forjando una imagen mental que luego, afanosamente, y a costa de perder su perfección, proyecta sobre una materia inerte y muerta, que le opone una extraña e incomprensible resistencia. ${ }^{44} \mathrm{El}$ ser se construye históricamente, busca y tiende a sus propias posibilidades, a aquellas que le dan conciencia y noticia de su propio poder. En la creación, es la materia misma la que tiende a su máxima potenciación, ofreciendo al artista el material vivo para su propio juego de poder. Tan sólo la obra de arte verdadera, aquella que es fruto del poder, es capaz de despertar en nosotros la conciencia de nuestro propio poder, concitándonos a crear, recreando. Como dice Platón en el Banquete, al hombre mortal sólo se le han dado dos formas de inmortalidad: mediante la procreación física o la espiritual. Pero toda procreación es fruto de un eros que busca procrear en la belleza. Tan sólo en la belleza, y mediante la belleza, eros se vuelve poiesis, poder creador. De este modo el poder creador se plasma en obra de arte, la única que mediante su recepción permite a otros poderes volverse creadores. La verdadera cadena hermenéutica del arte es una cadena de una voluntad que busca implementarse a sí misma, volverse fecunda, reproducirse bellamente en una concatenación de obras de arte, de verdaderas creaciones, en las que la voluntad muestra, al mismo tiempo que conoce, su poder.

\section{EPÍLOGO}

Vemos, por tanto, que la vía abierta por la inflexión metafísica llevada a cabo por Schelling en su filosofía, desde una metafísica del ser como sustancia a una metafísica del ser como voluntad, ha permitido que el ser entendido como voluntad se configure en el suelo metafísico para una concepción evolucionista y dinámica de la naturaleza y de la historia.

Esta metafísica de la voluntad ha evolucionado durante el transcurso del siglo XIX hacia una metafísica de la voluntad de poder que, si hemos de hacer caso

44 De aquí sin duda el rechazo nietzscheano a un platonismo vulgar que entiende la $m \hat{\imath}^{-}$ mesis bajo la figura del artesano que forja primero mentalmente un modelo ideal que luego, en la realización fáctica, pierde la hermosura y la belleza de su idealidad. A partir de este momento se establecería el más firme y radical divorcio entre realidad e idealidad. Sin duda el concepto platónico de mîmesis apela a una realidad más profunda y compleja, que queda claramente iluminada por su concepto de belleza como lugar de la procreación, de la creación y es en esta idea de la cadena hermenéutico-poiética de una obra de arte sobre otra donde más fielmente retratada queda. 
a Heidegger, se configura con Nietzsche en una verdadera metafísica estética, entronizando al artista en símbolo viviente de la voluntad de poder, en cumbre y corona de una metafísica histórica. En este punto el Idealismo, culminado y superado por Schelling, parece coincidir plenamente con el proyecto romántico, ya formulado esquemáticamente por Schiller en su Kalias o cartas sobre la educación estética del género humano, en las que proponía que el Arte debía guiar y alumbrar el nacimiento de la nueva Humanidad, uniendo de este modo lo espiritual y lo instintivo, lo ético y lo pasional; o con el Más antiguo proyecto del Idealismo alemán, cuya autoría se reparten indistintamente Hegel, Schelling y Hölderlin, donde se augura el nacimiento de una mitología de la razón en la que razón y simbolismo celebrarán sus desposorios ${ }^{45}$, proyecto que Nietzsche parece haber hecho realidad con su profeta Zaratustra, en un poema simbólico de innegable belleza, fruto del ejercicio de la voluntad autodestructiva de Nietzsche en el alzamiento de sí, y que las vanguardias malinterpretaron, hundiendo el arte en una banalización de la que aún no ha conseguido recuperarse.

No obstante, el fracaso de las vanguardias no afecta radicalmente a esta metafísica estética porque la comprensión metafísica del arte, y de la obra de arte, nos permite asumir un concepto más amplio de arte que entiende, en la línea de Leibniz y Spinoza -verdaderos progenitores de esta metafísica de la voluntad que se inaugura con Schelling-, como obra de arte todo lo que convoca y concita al poder creador, sea éste organismo natural, proyecto político, realidad económica o lo que fuere. Por supuesto no aquello que concita a la mera repetición, a la copia, y en esto Platón tenía toda la razón al expulsar de su ciudad ideal a los artistas miméticos, sino a la variación, a la repetición recreadora, a aquella que no sólo se dedica a crear, sino a crear recreando, a mostrar su propio poder en la forma de una poiesis que varía el mundo, recreándolo. Esta línea, a la que apela la metafísica de Eugenio Trías formulada en su filosofía del límite, ${ }^{46}$ es la asunción radical de que el mundo es la variación recreadora de una voluntad de poder que no parece tener ni principio ni fin.

45 Bubner, R. (1973), «Das älteste Systemprogramm der deutschen Idealismus. Studien zur Frühgeschichte des deutschen Idealismus», en Hegel-Studien, Band 9, Bonn.

46 Pérez-Borbujo, F. (2005), La otra orilla de la belleza. En torno al pensamiento de E. Trías, Herder, Barcelona, págs. 423-427. 
FERNANDO PÉREZ-BORBUJO ÁLVAREZ es Profesor Titular de Filosofía en la Universidad Pompeu Fabra (España)

Líneas de investigación:

La filosofía alemana del siglo XX (Idealismo alemán, Schopenhauer, Nietzsche, Freud).

La filosofía española del XX (Unamuno, Ortega y Gasset, D’Ors, Zambrano, Trías).

Publicaciones recientes:

(2010) Tres miradas sobre el Quijote: Unamuno, Ortega y Zambrano, Herder, Barcelona, (ISBN 978-84-254-2666-7)

(2007) Veredas del espíritu. De Hume a Freud, Herder, Barcelona, (ISBN 978-84-2542506-6)

Dirección postal:

Universidad Pompeu Fabra

Despacho 230, Jaume I

c/ Ramón Trías Fargas, 25-27

08005-Barcelona (España)

Dirección electrónica: fernando.perez@upf.edu 